\title{
How Does Video Platform Contribute to the Dissemination of Chinese Talent Shows? Case Study of Chuang 2021
}

\author{
Chenyang Kong ${ }^{1, *}, \dagger$, Jiayi Zhang ${ }^{2, \dagger}$, Xiyue Zhang ${ }^{3, \dagger}$
}

\author{
${ }^{1}$ Beijing Haidian Kaiwen Academy, 100097, Beijing, China \\ ${ }^{2}$ Beijing Haidian Foreign Language Academy, 100097, Beijing, China \\ ${ }^{3}$ Saint Paul American School, 100192, Beijing China \\ *Corresponding author.Email: chenyangkong@yeah.net
}

${ }^{\dagger}$ These authors contributed equally.

\begin{abstract}
Chinese talent shows are becoming popular in recent years, and producers have incorporated more ways to propagate their shows. Common marketing can be divided into two levels: online and offline. Among all the online marketing strategies employed by producers of Chinese talent shows, we focus on the video platform's contribution to the dissemination of talent shows. We first researched the dissemination of online videos and social media. To investigate how the video platform affects audiences' choices, we conducted a survey and collected 100 answers. Then, we analyzed the result of the survey, together with the essays we read. In conclusion, video platforms provide an advantageous environment for disseminating Chinese talent shows, providing a platform for shows to propagate themselves, attracting new audiences, and expanding influence.
\end{abstract}

Keywords: Chuang 2021, Talent shows, Video platform, Dissemination, Social Media

\section{INTRODUCTION}

Talent Shows have become gradually popular in China. Young people dance and sing during the whole program, and the audience vote for them to help them stand out. The programmers use online strategies to attract more potential audiences and engage more voters to help the program create more benefits. Carefully analyzing the dissemination of talent shows, we found that video platforms, which combine video and social media characteristics, may play a big role in propagating talent shows [1]. Besides intended operation and marketing, the Internet and Internet users unintentionally publicize information that propagates talent shows.

We take the recent Chinese program "Chuang 2021" as an example to analyze the relationship between Chinese talent shows and online video platforms. Chuang 2021 is positioned as an "international youth cultural exchange program". Viewers can see their favorite participants in episodes released on video platforms and vote to support them. According to the vote of each participant, a certain number of participants with the most vote can make their debut as an idol band.

The following essay will analyze and discuss the true mutual influence between the Internet and Talent show. The expected result is that Internet can positively influence the dissemination of Talent shows.

\subsection{The Development of Chinese Talent Show}

The talent show is where participants perform singing, dancing, lip-syncing, acting, martial arts, playing instruments, poetry, comedy, or other activities to showcase skills. Chinese talent show history can be roughly divided into four stages. The first stage is the youth singing competition, which was first held in 1984.

The second stage is the national talent show stage, which pays no attention to age and appearance. The event was modeled after American Idol in the United States. The domestic representative programs are Super Boy of Hunan TV and My Style My Show of Dongfang TV. The third stage, "The Voice of China" (2012), is a 
typical example in which voice was the most important factor and singing strength was highly emphasized.

The last stage, namely the present stage, develops idols who sing and dance on the stage. In 2015, X Fire was the first idol cultivation program in China. Along with the development, there were also many new idol cultivation programs.

\subsection{Chinese Talent Shows and Media}

In the past, talent shows could only be broadcast through TV [2]. When mobile networks and mobile phone clients were developed, talent shows paid attention to interactivity and user participation [3]. Many shows interacted with audiences by utilizing massages or texts. For example, Super Boy collected the vote from audiences by messaging.

Nowadays, the audience's taste gradually has improved, and they are more willing to see various shows or programs with good production, big-name stars, originality, and compactness. In such a competitive industry, the higher the investment, the higher the risk. The homogenization of Chinese online shows is a significant issue in the Chinese market, increasing marketing risk. As a result, it is increasingly important to promote intensively to stand out from the mass of programs.

With the development of technology and the Internet, especially mobile Internet, viewers could watch talent shows through mobile applications on phones and computers. Since the Internet connects every independent individual, the appearance of new media connects network broadcasting platforms with TV stations and TV program production companies.

\subsection{Development of Media}

In the 21 st century, mobile phones and the Internet have developed unprecedentedly. People now incorporate multiple media forms, and the information previously delivered by several media has been integrated into one device. This connection of media provides a channel for the communication of anyone who has access to the Internet [4]. Producers of talent shows recognize this efficient channel and fully utilize it. Audiences are easily engulfed by information from these producers and entertaining companies.

\section{METHODOLOGY}

\subsection{Structure}

After reading essays in the same field, we proposed a model for analyzing the role of video platforms. The contribution can be divided into two branches: producers of talent shows and audiences. The producers of talent shows propagate their shows by utilizing video platforms and uploading their shows on these video platforms. From the perspective of audiences, users on video platforms act as audience and co-creators.

\subsection{Survey and Subject}

We conducted a survey investigating people's attitudes toward the content of Chinese talent shows on video platforms. The survey contains eight questions. Because of the pandemic, we distributed an online social media survey, and the samples we gathered were convenient. We totally received 100 answers, and 57 of them said that they had watched Chinese talent shows.

We chose one specific Chinese talent show called Chuang 2021 as the subject of this study because this show is the last talent show in the market, which has the latest marketing strategies [5]. Two examples of the video platform are Tok-Tok and Bili Bili, for the sake of their popularity. The data of these two platforms were acquired through two data platforms, Douchacha and HuoShanYun [6]. These data will not be presented exclusively as one part of this paper; rather, they are included in the analysis below when needed.

\section{RESULT}

We totally received 100 answers, and 57 of them said that they had watched Chinese talent shows.

Among the questions in our survey, two questions provide useful evidence for this paper.

The first question asks about how people get to know about talent shows. Participants could only select one answer. $57.98 \%$ of the participants learn talent shows by Weibo, a social media similar to Facebook. $10.53 \%$ of the participants learn talent shows by WeChat or QQ, which are social media similar to Line. $26.32 \%$ of the participants learn talent shows by video platforms like Bili Bili. The rest of the participants learn from other ways like an introduction by others and TokTok.

Another question that contributes to our paper is "What eventually motivates you to watch talent shows?". Participants could select several answers. $33.33 \%$ of the participants watch talent shows because of the recommendation of friends. $49.12 \%$ of the participants finally watch talent shows because of marketing strategies on social media. $54.39 \%$ of the participants finally watch talent shows because of video clips on video sites. $40.35 \%$ of the participants finally watch talent shows because of short videos on short video platforms. 


\section{ANALYSIS}

\subsection{From the Perspective of Producers}

As producers, the personnel of the talent show makes effective use of video platforms. Various shows are promoted during the pre-launch and broadcast period of talent shows to create hot topics, increase popularity, and expand the market.

\subsubsection{Characteristics of Social Media}

Online video sites and short video applications, as emerging media, contain the inheritance of traditional media and carry many new features of their own, such as interactivity that traditional media do not have. Interaction between the talent shows and audiences can build up the emotional link between them and propagate the shows to more people. Video platforms can provide a place for talent show producers to interact with audiences for its characteristics of social media.

Social media is characterized by equal communication, conducive to maintaining friendly communication between programs and potential audiences and deepening relationships [7].

Producers of Chuang 2021 used Tok-Tok and Bili Bili as two of the major platforms to market their program. These two platforms have characteristics of social media that contribute to the spread of Chuang 2021: users of Tok-Tok and Bili Bili can follow other users, chat with other users, comment on videos, and like posts.

Producers of Chuang 2021 also have official accounts on Tok-Tok and Bili Bili, where they release some clips of the daily life of trainees. These interesting scenes can attract young people to watch shows.

\subsubsection{Non-competitive Strategic Alliance}

Chuang 2021 officially sent interesting clips on TokTok and made full use of Tok-Tok's "Duet" function. Through the "Duet" feature, users can interact with the video uploader through shooting videos themselves and win rewards. Tok-Tok network operation data on the Douchacha platform shows nearly 8 million videos published every day. The official account of Chuang 2021 on Tok-Tok has attracted 1.214 million followers.

Bili Bili is one of the top video sites in China and has a very young user base. Chuang 2021 has joined forces with Bili Bili to encourage the secondary creation of the show by launching fan creation competitions. This type of promotion has resulted in the talent show gaining widespread attention across the video site, with fans participating and regular viewers joining in for the rewards.
For example, an activity called "funny clip of a player in the Chuang 2021" was launched last year. It allowed more people to participate and skillfully converted the audiences of the Bili Bili platform into reporters, continuously attracting more audiences. According to the data on the HuoShanYun website and operational content analysis, two officials, Chuang 2021, have uploaded a total of 140 videos on Bili Bili. On Bili Bili, users can label uploaded videos. According to the HuoShanYun platform, videos labeled "Chuang 2021" have been viewed more than 200 million times and received more than 2 million comments.

This seems like a very simple way to bring much fun to the audience. In the past, when people watched the show, they would at best talk about it on social media. However, this time, there are videos to participate in and prizes to win. Furthermore, this online interactive mode enhances the audience's sense of participation in watching the talent show. This increases the audience's interest in the show and extends its reach, spreading the participants' stage and carpet-bombing their memes, achieving the best results with the same input.

\subsubsection{AI Algorithm Recommendation}

The attractive nature of video platforms is responsible for the dissemination of talent shows. By analyzing past viewing records of users, video sites will recommend corresponding videos that may attract potential users [8]. Users who have watched talent shows before will be the target audiences of new talent shows. On Tok-Tok and Bili Bili, as long as users have watched videos about talent shows or uploaded related videos, the platforms will automatically recommend videos about, for example, Chuang 2021.

The producers of talent shows cooperate with video platforms to further expand their influence. Each site has its characteristics, so they hold different activities and competitions. Taking Chuang 2021 as an example, Bili Bili held various competitions or activities to encourage video clips or recreation. Many Bili Bili users uploaded video clips that affected other users who were unaware of the talent show. In the three campaigns last year, 13,454 videos were uploaded, viewed over 191 million times. On short video platforms like Tok-Tok, recreation also takes place. During Chuang 2021, users can co-produce with the participants in that talent show, which gives users a feeling of engagement. These forms of recreation bond with preexisting audiences and attract new audiences to watch talent shows [9].

One question in the survey we conducted asks about the effect of recreation videos on people's willingness to watch talent shows. $54.39 \%$ of participants said that video clips on video platforms finally motivate them to watch the shows, and $40.35 \%$ of the participants are motivated by short videos. Therefore, cooperating with 
video platforms is an effective and efficient way for talent show producers to propagate the shows.

\subsection{From the Perspective of Audiences}

Audiences are also a large group of people who give feedback and influence the Talent Shows.

\subsubsection{Commenting and Potential Audiences}

Some people choose only to watch shows and leave comments down on the comment area to express their thoughts about the show. They do not use other devices and forms of media to recreate and reach other desires. These people take the largest part of the audience in the current talent show market. The comments can be divided into three categories: fans expressing their enthusiasm toward participants of talent shows, viewers focusing on the shows, and critics finding fault with the talent shows.

Without a doubt, every single comment act like propaganda, whether negative or positive [10]. When potential audiences see these comments, they will wonder whether the comments are authentic or the show is worthy of watching. For the sake of their curiosity, they will go and watch the talent shows. Therefore, potential audiences are transferred into audiences.

\subsubsection{Commenting and Potential Audiences}

There is also another group of audiences who are cocreators. Those people are more eager to express their opinion and thus to influence other people. The purpose of doing this is very simple: getting more people to notice their favorite idols and create larger commercial impacts for idols. This kind of relationship creates a new culture called fans community [4].

People who love the same person will form a group to share their thoughts and get more information about their same idols. Actually, those people play the role of key opinion leaders when they engage in the fan's community. A key opinion leader is a community member whose expert advice is respected by others in their fields. Some fans in their fans communities are also the key opinion leaders who provide a large amount of information about their idols and even influence outsiders who have no understanding about idols. Fans are the ones who bring large financial income for the Talent Show and Idols themselves. The data they made gives the market a great indicator of idols' ability. Some people need to vote for their idols during the competition to help their idols to achieve a better result. The talent show's organizers receive financial benefits by acquiring the money raised by fans.

Those fans are also beneficiaries in this chain. Some people chose to use the original videos and took the organizer to recreate the video to earn money. Fans may focus on one idols' performance on stage to add different performances together to form a complete video to gain financial access. With more and more people click their recreated videos, recreators gain money from the video platform. Through this material method, fans get more real benefits to keep them support their idols. Some fans even take making videos as their main job to sustain their livelihood. The videos those fans recreated also give an impact on the Talent Show organizer. Some people choose only to watch video clips instead of watching the whole shows on certain official video websites. Some people even have a negative impression about certain shows when they only watch a video clip about the show and thus form their original impression.

There is no denying that video platform plays an important role for the dissemination of talent Shows. Based on the survey we inducted before, $26.32 \%$ of people get information about one new talent Show through video websites [11]. The video platform is the main motivator to help a person finally decide to watch the shows. $54.39 \%$ of people choose to watch the show due to the video clips on the video platform, which strongly shows the impact of videos on the revenue of the show's sponsor.

\section{CONCLUSION}

As a successful case of positively taking advantage of online video platforms to promote the talent show, Chuang 2021 provides valuable experience in understanding the marketing characteristics of variety shows in the age of online media, marketing and improving the brand influence of variety shows. The producer of talent shows takes advantage of the interactivity of video platforms, but also audiences intentionally help propagate the talent shows.

\section{REFERENCES}

[1] Juan Shi, Ping Hu, Kin Keung Lai, Gang Chen (2018), Determinants of users' information dissemination behavior on social networking sites: An elaboration likelihood model perspective. Internet Research, Vol. 28 Issue: 2, pp.393-418, https://doi.org/10.1108/IntR-01-2017-0038.

[2] Hao Yan. Research on the Innovation of TV Program Planning and Compilation [J]. Guide to News Research, 2014, (16) : 66-66.

[3] Shin-Ming Cheng, Vasileios Karyotis, Pin-Yu Chen, Kwang-Cheng Chen, and Symeon Papavassiliou(2013), Diffusion Models for Information Dissemination Dynamics in Wireless Complex Communication Networks. Journal of Complex Systems Volume 2013, Article ID 
972352, $13 \quad$ pages

http://dx.doi.org/10.1155/2013/972352

[4] McQuail, D. (2010). McQuail's mass communication theory. Sage publications.

[5] Qi Chenyang(2017), Research on Marketing Strategy of TV Variety Show under New Media Background. College of Management, Zhejiang University of Media and Communications.

[6] Christopher Egger(2016), Identifying Key Opinion Leaders in Social Networks: An Approach to use Instagram Data to Rate and Identify Key Opinion Leader for a Specific Business Field. TH Ko ln University of Applied Sciences Institute of Informatics.

[7] Cheng, S. M., Karyotis, V., Chen, P. Y., Chen, K. C., \& Papavassiliou, S. (2013). Diffusion models for information dissemination dynamics in wireless complex communication networks. Journal of Complex Systems, 2013.

[8] Srinidhi Kulkarni V \& Mr. Somashekar T(2013), Information Dissemination Models in Generalized Social Networks. International Journal of Engineering Research \& Technology (IJERT) NCRTS'14 Conference Proceedings ISSN: 22780181. https://www.ijert.org/research/informationdissemination-models-in-generalized-socialnetworks-IJERTCONV2IS13069.pdf

[9] Stray, J., Vendrov, I., Nixon, J., Adler, S., \& Hadfield-Menell, D. (2021). What are you optimizing for? aligning recommender systems with human values. arXiv preprint arXiv:2107.10939.

[10] Siddiqui, S., \& Singh, T. (2016). Social media its impact with positive and negative aspects. International journal of computer applications technology and research, 5(2), 71-75.

[11] Chou, Y. F., Huang, H. H., \& Cheng, R. G. (2013). Modeling information dissemination in generalized social networks. IEEE communications letters, 17(7), 1356-1359. 